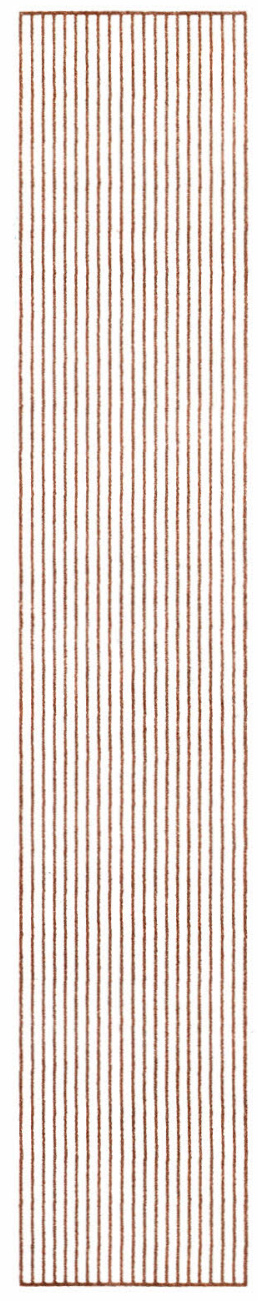

\title{
UN EJERCICIO DE
}


LUZ GUIOMAR MALDONADO PEREZ

Docente Departamento de Ciencias Humanas Universidad Autónoma de Manizales

$A \| I O R A$

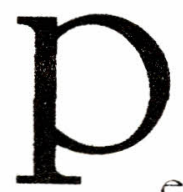

ensar en el placer de la lectura es un dejar la obligatoriedad, un deleitarse con cada una de las palabras, un develar sentidos, una ruptura en la que entran en juego códigos que chocan, desconocidos, desconcertantes, irritantes, asignificantes, y en ese entrecruzamiento y develamiento de códigos se encuentra un primer grado del placer. Otro momento del placer es ese comenzar que pide no ser interrumpido hasta el final, un atrapamiento del texto, el lector aprisionado por el libro y en el 
libro, en un dificil dejarse, en un no querer separarse hasta que todo quede de alguna manera dicho, como entre dos amantes que se despiden. Hay una tercera instancia del placer, la Locritura; el texto se convierte en un pretexto para la escritura, no para hacerlo de la misma manera como el autor lo hizo, es tan "sólo el deseo de escribir que el escritor ha tenido, es más: deseamos el deseo que el autor ha tenido del lector mientras escribia, deseamos ese ámame que reside en toda escritura". (1) Es una posibilidad de poner en Escritura la lectura.

Los dos ejercicios de escritura que aparecen a continuación parte de este tercer momento del placer, de un volver a decir el texto, de escribirlo desde esa fusión intima entre libro-lector, como un ejercicio de escritura si se quiere, como un pretexto de la misma también, incluso, si se quiere, solamente como un ejercicio desde el aula de clase, desde la mirada de dos cuentos de García Márquez "Eva está dentro de su gato" y "Ojos de perro azul". Dos cuentos que en la lectura no solamente deleitan desde su narratividad, sino que además piden no ser interrunpidos y desembocan en el deseo de escribir.

\section{AMFOBAD}




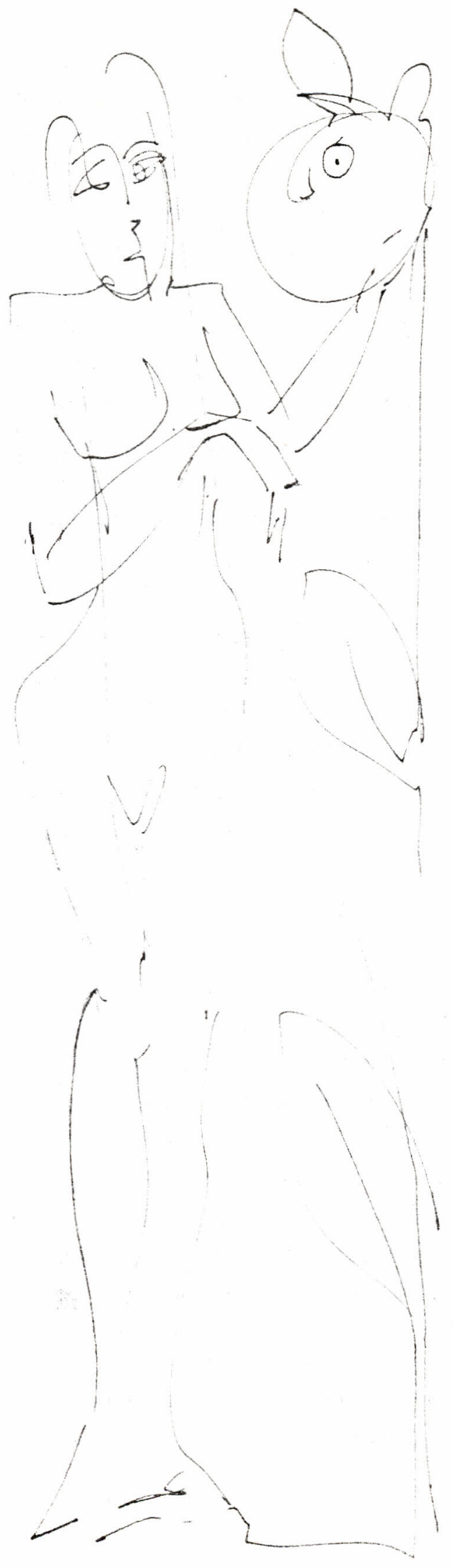

Flotando entre los recuerdos y temores, navegando en la nada de la muerte, jugando en la temporal atemporalidad, ahi está Eva, heredera de la belleza, última representante de esa estirpe. belleza que la tortura, la acosa, dolor representado en animalitos que la carcomen por dentro tal como a sus antepasados, deseo lascivo de los hombres que la observan, deseo que Eva rechaza; temor a ser mirada como mujer; mejor, el dolor de ser bella que aceptar el deseo que su belleza produce, animalitos carcomiéndola, purificándola del deseo que ella despierta.

Eæa és Eva, parece siempre escapándose a la realidad, una realidad, finalmente inexistente, su casa se encuentra llena de polvo y arsénico; siglos han pasado desde los pocos momentos en que ella se encuentra flotando entre recuerdos y temores como si con ello pudiera evitar la realidad de su muerte: siglos han pasado desde que conenzó a sentir ese deseo carnal de comerse una naranja, deseo antes rechazado por temor al ciclo biológico, en últimas un temor canibal. Deseo de volver a la animalidad, ser gato, gozar de sus privilegios. de su sensualidad de movimiento, aprovecharse de ello sin tener que enfren- 
tar el deseo de los otros, tarde va para la aceptación de su condición de lo femenino, no hay posibilidad de cuerpo siglos han pasado, y además, en eae nuevo cuerpo, otra vez un miedo canibal. Siglos han pasado desde que llegó la muerte más sólo instantes en la linealidad de los recuerdos, temores y deseos. la muerte surge como un limbo. no hay otros, no hay nada. oscuridad y vacio, la mente divagando en parajes perdidos.

Aquí, por lo menos. no sentimos la putrelacción del cuerpo, pero de resto como en los demás cuentos de la serie, la muerte absurda e inoperante trabaja en las mentes desquiciadas de los muertos, sujetos a la locura etena de flotar en sus recuerdos, temores. deseos.

Encontrarse en los sueños

luego la angustia del olvido. te busco cada mañana, a cada hombre que veo le digo ansiosa las palabras mágicas que permitirán el reconocimiento "Ojos de perro azul", pero todo es inutil, ni siquiera se quién es el dueño del sueño. Nos encontramos en un sueño, tú me observas, ves mi rostro a pesar de estar yo de espaldas, no permito que me toques, quizás todo se desvanezca y al abrir la puerta... sólo los sueños de otros.
El irónico encuentro, doloroso en el olvido, tú olvido, porque yo cada mañana te recuerdo y salgo a tu encuentro y continuo en una búsqueda infructuosa. Regresar al sueño, tampoco alli encuentro la clave, tú no dices como encontrarte. no sabes donde estamos y sólo me recuerdas en el eterno instante de nuestro encuentro, instante en el que incluso recuerdas los otros encuentros, ahi están juntas la ironia y el dolor. El despertar golpea como una profunda carcajada que hiere hondo porque se que en ese momento tú me olvidas y que cada vez que yo pronuncie "ojos de perro azul" los otros me mirarán extrañados penśando incluso que estov loca, tal vez el sueño sea la pesadilla diaria y la realidad sea el relax tormentoso de nuestro encuentro en el que tocamos es imposible, en el que corremos el riesgo de mezclarnos en otros sueños, en el que amarnos es una mezcla extraña de miradas y palabras. Tal vez es mejor asi, cada noche, o cada amanecer, o cada mañana estamos expectantes ante el fugaz instante en que comienzan a encontrarse nuestras miradas.

(1) BARTHEd. Roland. El susurro do kenguaje. Tr C Femández. Barcelond: ediciones Paidós. 2a. cd. 1994. pag ti) 